\title{
Full Paper \\ Primary prevention of venous thromboembolism in medical and surgical oncology patients
}

\author{
A Stanley*,I and A Young ${ }^{2}$ \\ 'Birmingham Treatment Centre, City Hospital, Dudley Road, Birmingham B 8 7QH, UK; ${ }^{2} 3$ Counties Cancer Network, Gloucester Business Park, 5220 \\ Valiant Way, Gloucester GL4 4FE, UK
}

Recent data suggest that patients with a malignancy have a seven-fold increased risk for venous thromboembolism (VTE) compared with those without cancer, suggesting that these patients may benefit from thromboprophylaxis. Mechanisms for the prevention of thromboembolism can be divided into two broad categories: mechanical and pharmacological. Although generally used in combination with pharmacotherapy, little evidence exists for the efficacy of mechanical modalities either in the broader population of patients at risk for VTE or for patients with cancer specifically. A recent study using graduated compression stockings (GCS) for thromboprophylaxis showed no support for the use of stockings in acute stroke patients. Established pharmacological modalities, including warfarin, unfractionated heparin (UFH), low-molecular-weight heparin (LMWH), and the factor Xa inhibitor fondaparinux, have been shown to reduce risk for VTE in general medical and surgical populations. In medical cancer patients, only limited data are available for the efficacy of thromboprophylaxis. In contrast, considerable evidence indicates that thromboprophylaxis is warranted in patients undergoing cancer surgery. The most recent evidence suggests that catheter-related thrombosis is not prevented by current pharmacological modalities. On 22 May 2009, a group of clinicians based in the United Kingdom (UK) met in London, UK, to evaluate recent data on cancer thrombosis. This article (the second of four) briefly reviews key data on the prevention of VTE in medical and surgical oncology patients, providing context for a brief transcript of the surrounding discussion and a consensus statement, developed by meeting attendees, on the implications of this information for UK clinical practice. British Journal of Cancer (2010) I 02, SI0-SI6. doi:I0.1038/sj.bjc.6605600 www.bjcancer.com (c) 2010 Cancer Research UK

Keywords: venous thromboembolism; thrombosis; prevention

It has been well known since the 19th century that patients with cancer have an increased risk for venous thromboembolism (VTE) compared with those without cancer. Recent investigations suggest that, overall, patients with a malignancy have an approximately seven-fold increased risk for first VTE compared with those without cancer, with risk ranging from a low of 1.6-fold increased risk in patients with head and neck cancers to a 28 -fold increase in patients with haematological malignancies (Heit et al, 2000; Blom et al, 2005).

Clearly, the data summarised above indicate that the risk for thromboembolism in patients with cancer is extremely high, and show the need both for effective thromboprophylaxis to prevent an initial event and adequate preventative efforts in patients who have already had an event. Adequate thromboprophylaxis is particularly important in light of the impact of thromboembolism on survival. For example, among patients with colorectal cancer in the United States, VTE was a significant predictor of death within 1 year of cancer diagnosis among patients with local (hazard ratio 1.8) or regional state disease (hazard ratio 1.5) (Alcalay et al, 2006). Similarly, an analysis of a large registry of patients with cancer $(N=235149)$ found that thromboembolism was a significant

*Correspondence: Dr A Stanley;

E-mail: andrew.stanley@westmidlands.nhs.uk predictor of decreased survival during the first year for all cancer types, with hazard ratios ranging from 1.6 to 4.2 (Chew et al, 2006).

Despite the profound impact of VTE on survival, it is apparent that there is a gap between recognition of VTE as an important patient safety issue in patients with cancer and adequate treatment (Kakkar et al, 2003). Risk assessment of VTE is not routinely carried out in the United Kingdom. The FRONTLINE survey, a comprehensive global survey of thrombosis and cancer, collected data on the perceived risk and patterns of practice with regard to VTE in cancer among patients undergoing surgical and medical management of their malignancy. Responses from nearly 4000 health-care providers identified marked differences in the use of thromboprophylaxis in surgical and medical patients. More than $50 \%$ of surgeons reported that they initiated thromboprophylaxis routinely; in contrast, medical oncologists reported using thromboprophylaxis in less than $5 \%$ of medical patients (Kakkar et al, 2003). Notably, almost $20 \%$ of respondents worldwide reported using aspirin for thromboprophylaxis, despite the lack of reliable evidence for preventative use of this agent.

On 22 May 2009, a group of physicians and other health-care providers based in the United Kingdom met in London, UK, to examine the most recent data on cancer-associated thrombosis and its implications for UK clinical practice. This article, which is the second in a series of four covering broad topics in cancer thrombosis, includes a summary of extant information on the secondary prevention of VTE in patients with cancer, a discussion 
on the relevance and relative importance of these data, and a consensus statement developed by attendees on the implications of this information for UK clinical practice.

\section{OVERVIEW: MODALITIES FOR THE PRIMARY PREVENTION OF VTE}

Mechanisms for the prevention of thromboembolism can be divided into two broad categories: mechanical and pharmacological. It should be noted that - throughout this discussion many modalities lack an evidence-based foundation for use in patients with cancer specifically; in these cases, an effort has been made either to select patients with cancer from the population, if data are available, or to summarise other population data, with the intention that the benefits and risks of these modalities are likely to extend to the patient with malignancy.

\section{Mechanical thromboprophylaxis}

Early and frequent ambulation of patients at risk for VTE is an important component of patient care. However, many patients with cancer are immobilised long term; these patients are candidates for mechanical thromboprophylaxis, generally used as an adjunct to pharmacological therapy. A number of mechanical thromboprophylactic modalities are available. They include electrical calf stimulation, intermittent pneumatic compression devices, graduated compression stockings (GCS), and venous foot pump devices (Geerts et al, 2008). These modalities have in common a relative lack of evidence from prospective, randomised, controlled trials for their efficacy in any patient population and have not been tested specifically in patients with cancer.

It is noteworthy that although patients with cancer are at increased risk for VTE, they are also at increased risk for bleeding (Prandoni et al, 2002). Although recognising their limitations, the most important advantage of mechanical thromboprophylaxis is the lack of bleeding potential - a significant concern in patients with cancer. Despite the lack of an evidence base, these devices represent an option for thromboprophylaxis, particularly in patients at high risk for haemorrhagic complications, and as an adjunct to medical thromboprophylaxis.

However, recent data from a randomised, controlled trial with GCS or routine care and avoidance of GCS showed no support for the use of thigh-length GCS in patients admitted to hospital, who are immobile because of acute stroke, in the prevention of deep vein thrombosis (DVT) (Dennis et al, 2009). Although it is not clear how many of these patients were taking aspirin, a logical extrapolation of these data is that immobile hospitalised patients with cancer should not be offered GCS alone.

\section{Pharmacological thromboprophylaxis}

Aspirin Although effective in reducing major thrombotic vascular events in patients with atherosclerotic disease, only limited evidence suggests that aspirin provides protection against VTE in hospitalised patients (Geerts et al, 2008). In general, aspirin should not be used as a primary pharmacological modality for thromboprophylaxis.

Warfarin The oral vitamin $\mathrm{K}$ antagonist warfarin is rapidly absorbed and has a long half-life of $36-42 \mathrm{~h}$ (Zacharski et al, 2005). Although effective as a thromboprophylactic modality, it has a number of important issues that make its use challenging, particularly in patients with cancer. In general, there is considerable inter-individual variation in response to warfarin, necessitating close monitoring to maintain the international normalised ratio (INR) within a target range (generally 2.0-3.0) (Zacharski et al, 2005). Diet, drug interactions, and other factors may change the response to warfarin over time. Issues specific to patients with cancer further complicate the use of warfarin in this population. The relationship between INR level, thromboprophylactic efficacy, and bleeding is not identical between patients with cancer and those without cancer. In a retrospective analysis that included DVT patients with and without malignancy who received vitamin $\mathrm{K}$ antagonists for 3 months with a target INR of 2.0-3.0, patients with malignancy had a clinically and significantly increased incidence of recurrence $(27.1 / 100$ vs 9.0/100 patient-years) and bleeding (13.3/100 vs 2.1/100 patient-years) compared with those without cancer (Hutten et al, 2000). Therapeutic INRs are also more difficult to sustain in patients with cancer, requiring more frequent monitoring (Bona et al, 1995).

Unfractionated heparin Heparin consists of a mix of sulphated mucopolysaccharides ranging from 3000 to $30000 \mathrm{Da}$ (mean $15000 \mathrm{Da}$ ) in molecular weight (Hirsh et al, 2008). Only about one-third of the heparin molecules possess the unique pentasaccharide sequence responsible for the anticoagulant effect of heparin. Heparin is administered by either continuous intravenous infusion or by subcutaneous injection, generally in accordance with published weight-based nomograms (Hirsh et al, 2008).

Although unfractionated heparin (UFH) has been shown to be effective in the prevention of VTE (see below), it is subject to important limitations. Heparin binds to a number of plasma proteins, endothelial cells, and macrophages, which influence its anticoagulant activity and contribute considerably to the variability of anticoagulant response observed in patients with VTE (Hirsh et al, 2008). Moreover, the kinetics of heparin clearance are complex, rendering the anticoagulant response to heparin nonlinear at therapeutic dosages. Equally important is the fact that heparin has a propensity to induce immune-mediated platelet activation, which can lead to heparin-induced thrombocytopenia (HIT), and it has an effect on bone metabolism, which can result in osteoporosis. Heparin has the advantage of rapid and complete reversibility with protamine sulphate, a property that may be useful in patients with cancer who, as a group, are at higher risk for bleeding than those without cancer (Hirsh et al, 2008). Heparin has a narrow therapeutic window; therefore, activated partial thromboplastin time must be monitored and the dosage adjusted accordingly.

Low-molecular-weight heparins Low-molecular-weight heparins (LMWHs) are derived by chemical or enzymatic depolymerisation of UHF. In general, these agents have a mean molecular weight of approximately $4000-5000 \mathrm{Da}$ (Hirsh et al, 2008). These lowmolecular-weight fragments have a reduced affinity for proteins and cells, resulting in an improved anticoagulant and pharmacokinetic profile compared with heparin, and a reduced propensity to cause HIT and osteoporosis. In the United Kingdom, five LMWHs are available for clinical use for specific indications, including dalteparin, enoxaparin sodium, tinzaparin, nadroparin sodium, and bemiparin. Dalteparin very recently gained a European licence for use as a thromboprophylactic in patients with cancer. Lowmolecular-weight heparins are generally administered in oncedaily, fixed, or weight-adjusted doses. Regular monitoring is generally not indicated, except in obese patients or in those with renal insufficiency (Hirsh et al, 2008).

Fondaparinux Fondaparinux is a synthetic derivative of the AT-binding pentasaccharide found in heparin and LMWH that acts through AT-mediated selective inhibition of factor Xa. It is administered at a fixed dose of $2.5 \mathrm{mg}$ for thromboprophylaxis (Hirsh et al, 2008). In most cases, coagulation monitoring is not needed in patients who receive fondaparinux.

Newer agents A number of newer agents have recently been made available for clinical use or are in the late stages of clinical development. None of these agents have been tested in patients with 
cancer specifically. Dabigatran, an oral, direct thrombin inhibitor, has been evaluated as a thromboprophylactic modality in patients undergoing hip (Eriksson et al, 2007a) and knee (Eriksson et al, 2007b) surgery and has been shown to be at least as effective as enoxaparin for the prevention of VTE in these high-risk patients. Rivaroxaban, an oral, direct inhibitor of activated factor Xa, has been shown to be superior to enoxaparin in the prevention of VTE after total knee replacement (Lassen et al, 2008; Turpie et al, 2009) and after total hip replacement (Eriksson et al, 2009). Apixaban, another oral inhibitor of factor Xa, is currently in late-stage clinical development (Shantsila and Lip, 2008; Jiang et al, 2009). Again, it is important to emphasise that no data are yet available for these newer agents in the cancer population, although US trials are ongoing with apixaban in patients with cancer.

\section{PRIMARY THROMBOPROPHYLAXIS IN MEDICAL CANCER PATIENTS}

Epidemiological studies have consistently shown that, overall, medical cancer patients have at least a four-fold increased risk for VTE; at the same time, they are at an elevated risk for bleeding during anticoagulation (Prandoni et al, 2002). Moreover, VTE is one of the most common and costly complications seen in patients with cancer, and recurrence rates are high both after and during anticoagulation. Careful weighing of the risks and benefits of anticoagulation and meticulous attention to dosing are required to successfully minimise the risks for both VTE and bleeding.

Few trials have specifically assessed the role of anticoagulants in patients with cancer undergoing chemotherapy who did not have another indication for anticoagulant therapy. In this study, patients with metastatic breast cancer were randomised to treatment with low-dose warfarin (adjusted to maintain the INR between 1.3 and 1.9) or placebo, with treatment continuing until 1 week after the end of chemotherapy. Warfarin was associated with a significant $(P=0.03) 83 \%$ relative reduction in the risk for VTE from 4.4 to $0.7 \%$ without an increased risk for bleeding (Levine et al, 1994). Two additional studies (TOPIC I and TOPIC II), which to date have appeared in abstract form only, assessed thromboprophylaxis in patients with metastatic breast cancer and non-small-cell lung cancer (NSCLC), respectively. TOPIC I enrolled patients with primary or secondary metastatic breast carcinoma treated with chemotherapy; these patients were randomly assigned to either LMWH certoparin or placebo for 6 months. In this study, the rate of VTE did not differ between the certoparin group (4\%) and the placebo group (4\%), suggesting that routine prophylaxis is not appropriate in this group. TOPIC II enrolled patients with inoperable, disseminated NSCLC undergoing chemotherapy; patients were randomised to either certoparin or placebo for 6 months. In contrast to the TOPIC I study, the incidence of VTE was reduced from $8.3 \%$ in placebotreated patients to $4.5 \%$ in the certoparin group. This risk reduction was not significant because of considerable underpowering of the study. Notably, risk for VTE correlated with histological stage, with stage IV patients experiencing the highest risk for an event and the greatest risk reduction with LMWH prophylaxis. The Fragmin Advanced Malignancy Outcome Study randomly assigned patients with advanced cancer to dalteparin or placebo for up to 1 year; in this study, there was no significant difference in the rates of symptomatic VTE between the two groups overall. However, a post hoc analysis of this trial found that survival improved with dalteparin among patients with a better prognosis (defined as survival for $>17$ months). Caution is warranted when interpreting these post hoc analyses (Kakkar et al, 2004).

More evidence is available to support the routine use of thromboprophylaxis in hospitalised general medical patients; this information may be extrapolated to hospitalised cancer patients.
The MEDENOX study randomly assigned 1102 hospitalised acutely ill medical patients to LMWH enoxaparin ( $40 \mathrm{or} 20 \mathrm{mg}$ ) or to placebo for 6-14 days. The primary outcome (VTE detected by bilateral venography or duplex ultrasonography between days 6 and 14 or documented PE) occurred in $5.5 \%$ of the enoxaparin $40 \mathrm{mg}$ group and in $14.9 \%$ of the placebo group (relative risk, 0.37 ; $P<0.001)$. Lower-dose enoxaparin did not reduce risk for VTE. There was no difference between the two groups in the incidence of adverse effects, including bleeding (Samama et al, 1999). Similarly, the PREVENT study found that LMWH dalteparin was associated with a $45 \%$ reduction in the relative risk of VTE in acutely ill medical patients $(P=0.0015)$, without substantial differences in the incidence of bleeding (Leizorovicz et al, 2005). Fondaparinux was examined in a placebo-controlled study that enrolled a population of $>800$ acutely ill medical patients; in this study, fondaparinux was associated with a $46.7 \%$ reduction in risk for VTE (Cohen et al, 2006).

\section{AMBULATORY PATIENTS}

Approximately $61 \%$ of the 1587071 cancer patient hospital episodes in the United Kingdom in 2007-2008 were ambulatory. However, given that the average length of inpatient stay is 7 days (median 3 days) (HES Online, http://www.hesonline.org.uk), the duration of thromboprophylaxis may be extended to "ambulatory patients" after discharge from the hospital. The publication of the first large thromboprophylaxis randomised, controlled trial in ambulatory cancer patients is imminent and may provide evidence upon which to base extended prophylaxis in ambulatory patients.

Thromboprophylaxis is warranted with specific ambulatory chemotherapy drug combinations that contain thalidomide and lenalidomide. The risk for VTE in patients with multiple myeloma receiving thalidomide has been found to range from 15 to $17 \%$ in combination with dexamethasone (Cavo et al, 2002; Rajkumar et al, 2006), and from 12 to $28 \%$ with thalidomide or lenalidomide in combination with other chemotherapy agents, including anthracyclines (Zangari et al, 2001; Bennett et al, 2006).

\section{THROMBOPROPHYLAXIS IN CANCER SURGERY}

Venous thromboembolism is common in all high-risk surgical populations. Patients with cancer undergoing surgery have been shown to have a two-fold or greater increased risk for fatal pulmonary embolism (PE) compared with those without cancer who are undergoing similar procedures (Geerts et al, 2008). Cancer is also an independent predictor of thromboprophylaxis failure.

Considerable evidence is available for the efficacy of a broad range of thromboprophylactic modalities in surgical patients. In 1988, Clagett and colleagues published a meta-analysis of low-dose unfractionated heparin (LDUH) that examined the efficacy of this modality in moderate- and high-risk general surgery patients. In this analysis, 29 trials in which over 8000 surgical patients were randomised to LDUH or control groups found the incidence of DVT to be $8.7 \%$ among treated patients, compared with $25.2 \%$ among controls $(P<0.001)$ (Clagett and Reisch, 1998). Notably, the overall incidence of major haemorrhage was identical in the LDUH and control patients.

The efficacy of LMWHs in cancer surgical patients has been assessed. A systematic review, published in 2007, pooled data from 26 randomised trials that included surgical oncology patients (Leonardi et al, 2006). Overall, the rate of DVT was $12.7 \%$ among patients who received pharmacological prophylaxis, compared with $35.2 \%$ for controls. There was no difference between UFH and LMWHs in efficacy, DVT location, or bleeding complications. Notably, dosage of LMWH was critical: high-dose LMWH (defined as $>3400 \mathrm{U}$ daily) was significantly more effective than low-dose treatment, lowering the rate of DVT from 14.5 to $7.9 \%(P<0.01)$ 
Table I Frequency of DVT in a trial comparing high-dose (5000 U) and low-dose $(2500 \mathrm{U})$ dalteparin in the total study group and in the subgroup with active malignancies (Bergqvist et al, 2002)

\begin{tabular}{|c|c|c|c|}
\hline & Dalteparin $(2500 \mathrm{U})$ & Dalteparin (5000 U) & $P$-value \\
\hline \multicolumn{4}{|c|}{ Total study group } \\
\hline $\mathrm{ITT}$ & 12.7 & 6.6 & $<0.001$ \\
\hline $\mathrm{CP}$ & 13.1 & 6.8 & $<0.001$ \\
\hline \multicolumn{4}{|c|}{ Patients with malignancy } \\
\hline ITT & 14.9 & 8.5 & $<0.001$ \\
\hline $\mathrm{CP}$ & |5.| & 8.8 & 0.001 \\
\hline
\end{tabular}

Table 2 Extended-duration LMWH (4 weeks) provides superior protection to short-term (I week) therapy (Bergqvist et al, 2002)

\begin{tabular}{lcccc}
\hline Event & $\begin{array}{c}\text { Short-term } \\
\text { enoxaparin } \\
\mathbf{( N = 1 6 7 )}\end{array}$ & $\begin{array}{c}\text { Extended } \\
\text { duration } \\
\text { enoxaparin } \\
\mathbf{( N = 1 6 5 )}\end{array}$ & $\begin{array}{c}\text { Risk } \\
\text { reduction } \\
\mathbf{( 9 5 \% ~ C l )}\end{array}$ & P-value \\
\hline $\begin{array}{l}\text { During double-blind period } \\
\text { All VTE }\end{array}$ & $20(12.0)$ & $8(4.8)$ & $60(10-82)$ & 0.02 \\
Proximal DVT & $3(1.8)$ & $1(0.6)$ & & \\
Distal DVT & $17(10.2)$ & $7(4.2)$ & & \\
PE & $1(0.6)$ & 0 & & \\
& & & & \\
At 3 months & $23(13.8)$ & $9(5.5)$ & $60(17-81)$ & 0.01 \\
All VTE & $4(2.4)$ & $2(1.2)$ & & \\
Proximal DVT & $17(10.2)$ & $7(4.2)$ & & \\
Distal DVT & $2(1.2)$ & 0 & & \\
PE & & & & \\
\hline
\end{tabular}

(Leonardi et al, 2006). Similar results were seen in a study by Bergqvist et al (2002) (Table 1).

Duration of prophylaxis with LMWHs after surgery for cancer has been prospectively addressed. In a double-blind trial enrolling patients undergoing planned curative surgery for abdominal or pelvic cancer, patients received enoxaparin $40 \mathrm{mg}$ daily for 6-10 days and then were randomised to receive either enoxaparin or placebo for another 21 days (Bergqvist et al, 2002). The primary end point was the incidence of VTE between days 25 and 31. At the end of the double-blind phase, the incidence of VTE was $4.8 \%$ among patients randomised to enoxaparin, compared with $12.0 \%$ among those who received placebo $(P=0.02)$; this difference persisted at 3 months. The rate of bleeding was similar in the two groups (Bergqvist et al, 2002) (Table 2).

The factor Xa inhibitor fondaparinux has not been prospectively assessed in patients with cancer in a dedicated trial. However, its efficacy was compared with that of dalteparin in a population of patients undergoing high-risk abdominal surgery, of whom the majority (approximately 56\%) were undergoing colorectal surgery (Agnelli et al, 2005). Among the 2048 patients who were evaluable for efficacy, VTE occurred in $4.6 \%$ of fondaparinux patients and $6.1 \%$ of dalteparin patients $(P=0.144)$. Major bleeding was more frequent among those who received fondaparinux (3.4\%) compared with those who received dalteparin (2.4\%) (Agnelli et al, 2005).

\section{PATIENTS WITH CENTRAL VENOUS CATHETERS}

The presence of a central venous catheter (CVC) in patients with cancer is known to predispose to upper-extremity DVT, resulting in arm swelling, discomfort, $\mathrm{PE}$, a predisposition to catheterrelated sepsis, and the potential for catheter replacement.
Several analyses have examined the impact of thromboprophylaxis on the rate of DVT in patients with CVCs. A 2007 metaanalysis, conducted by Kirkpatrick et al (2007), found that anticoagulant prophylaxis reduced the risk of all (combined symptomatic and asymptomatic) catheter-associated DVT, with relative risks by agent of 0.31 for LDUH, 0.37 for vitamin $\mathrm{K}$ antagonists, and 0.72 for LMWH. Although provocative, later analyses have not supported the conclusions of Kirkpatrick et al (2007), a meta-analysis, published by Chaukiyal et al (2008), included data from eight clinical trials enrolling a total of 1428 patients. There were no statistically significant differences in the risk of catheter-related thrombosis for warfarin, heparin, or LWMH vs placebo. No difference in the risk for bleeding between active treatments and placebo was observed (Chaukiyal et al, 2008).

Most recently, the efficacy of warfarin in reducing catheterrelated thrombosis was prospectively examined in the open-label, randomised WARP trial (Young et al, 2009). The UK study randomly assigned nearly 1600 patients with cancer to no warfarin, fixed-dose warfarin at a dosage of $1 \mathrm{mg}$ per day, or warfarin with the dosage adjusted to maintain an INR of 1.5 and 2.0. No difference in the rate of catheter-related thromboses was observed between the no-warfarin and warfarin group (relative risk, 0.99; $P=0.98$ ) (Figure 1). When the warfarin group was divided into those who received fixed-dose or adjusted-dose treatment, it was found that dose-adjusted warfarin was superior to fixed-dose warfarin in the prevention of catheter-related thromboses (3vs 7\%; $P=0.002)$. Major bleeding was infrequent in any group. A metaanalysis of warfarin intervention $v s$ control showed no thromboprophylactic advantage for warfarin (OR 0.75, CI 0.5-1.1; $P=0.1$ ) in 1356 cancer patients with CVCs (Young et al, 2009).

\section{GUIDELINES FOR THROMBOPROPHYLAXIS IN CANCER PATIENTS}

Multiple - and often inconsistent - guidelines have been developed in Europe and the United States to advise the use of thromboprophylaxis in patients with cancer. They include those developed by the European Society for Medical Oncology (ESMO), the American Society of Clinical Oncology (ASCO), and the American College of Chest Physicians (ACCP). This section will briefly review these guidelines to set the stage for a discussion of their relative applicability to UK general practice. Please refer to the complete guidelines before considering practice changes.

\section{ESMO guidelines}

- LMWH (3400-5000 U per day) or UFH (5000 U three times daily) is recommended in patients with cancer undergoing major cancer surgery; patients undergoing elective major abdominal or pelvic surgery should receive postdischarge prophylaxis for up to 1 month after surgery.

- Among patients undergoing neurosurgery, routine prophylaxis with LMWH is recommended.

- In medical patients, prophylaxis is recommended in hospitalised patients with cancer confined to bed with an acute medical complication.

- Prophylaxis is not recommended for ambulatory cancer patients receiving palliative chemotherapy for advanced disease, those receiving adjuvant chemotherapy and/or hormone therapy, or in patients with CVCs (Mandalá et al, 2008).

\section{ASCO guidelines}

- Hospitalised cancer patients should be considered as candidates for VTE prophylaxis in the absence of bleeding or other contraindications to anticoagulation. 
A

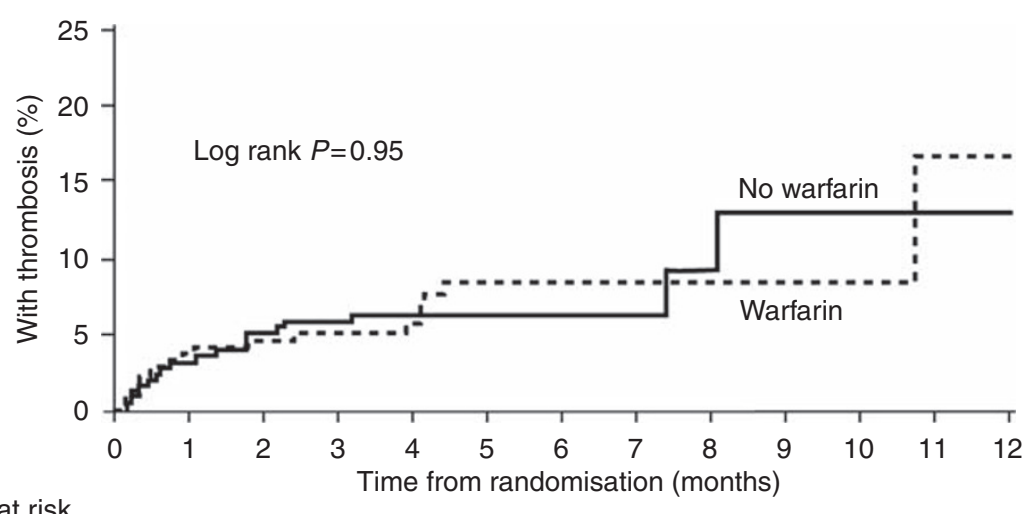

Number at risk

No warfarin 376

Warfarin 379

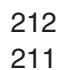

66

58

15

15

6

B

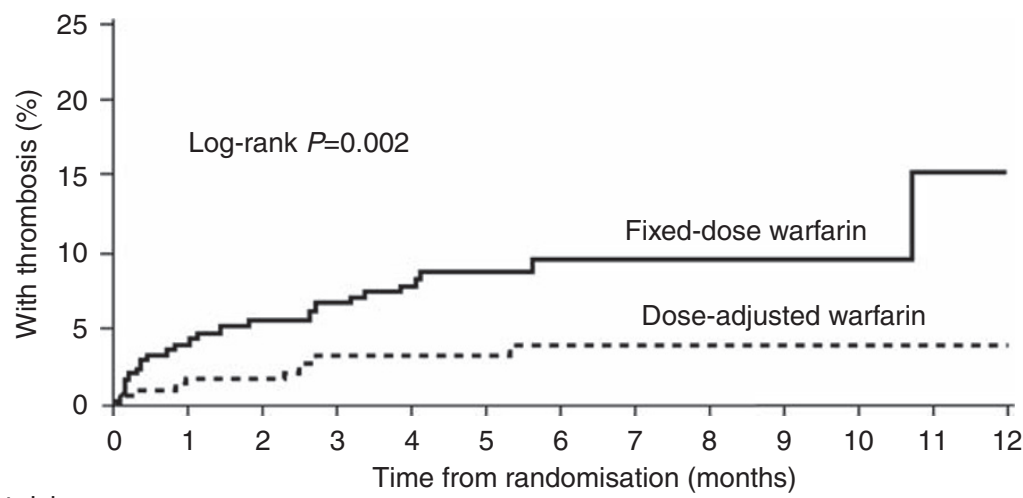

Number at risk

Fixed-dose

warfarin 452

Dose-adjusted

warfarin 438

272

78

84
26

39
12

18

Figure I Time to catheter-related thrombosis in a population of patients randomised to warfarin (fixed or dose adjusted) or no warfarin. (A) No warfarin vs warfarin; (B) fixed-dose warfarin vs dose-adjusted warfarin. Adapted with permission from Young et al (2009).

- Routine prophylaxis with an antithrombotic agent is generally not recommended for ambulatory patients with cancer during systemic chemotherapy, except in the case of patients receiving thalidomide or lenalidomide with chemotherapy or dexamethasone. In these cases, LMWH or adjusted-dose warfarin is recommended in patients with myeloma.

- All patients undergoing surgical intervention for malignant disease should be considered for thromboprophylaxis, initiated pre-operatively or as early as possible post-operatively, generally with LDUH or LMWH unless contraindicated because of active bleeding. Thromboprophylaxis should be continued post-operatively for 7-10 days and up to 4 weeks in certain patients. Mechanical methods may be added to pharmacotherapy but should not be used as monotherapy (Lyman et al, 2007).

\section{ACCP guidelines}

- Routine thromboprophylaxis is recommended for patients with cancer undergoing surgery. Specific modalities should be consistent with the recommendations for surgical subtypes.

- Bedridden patients with cancer with an acute medical illness should receive routine thromboprophylaxis, consistent with the guidelines for all high-risk medical patients.

- Thromboprophylaxis is not recommended for patients with cancer with indwelling CVCs.
- Routine thromboprophylaxis for the primary prevention of VTE is not recommended for patients with cancer receiving chemotherapy or hormonal therapy (Geerts et al, 2008).

\section{DISCUSSION}

Faculty: Are there biomarkers available for identifying high-risk populations?

Ajay K Kakkar: We have been looking at isoforms of tissue factor that have interesting properties. Total tissue factor does not predict risk, however. In light of current data, a recommendation to provide prophylaxis to all patients receiving chemotherapy is not supported.

Faculty: It is difficult to know where the cutoff should be in terms of providing thromboprophylaxis. While all the therapies discussed today provide impressive risk reductions, the risk for an event is quite low.

Ajay K Kakkar: In the context of cancer treatment, there has been some discussion around the frequency of thromboembolic events that the medical oncologist would consider sufficient to justify primary prophylaxis. One figure that has been suggested is in excess of $10 \%$, with some suggesting that the rate would need to be $15-20 \%$ to justify thromboprophylaxis. Trials in unselected populations yield a frequency of approximately $4-5 \%$. This frequency is approximately as high as we see in other therapeutic 
areas. In patients undergoing hip arthroplasty, we know that 1 week of prophylaxis in hospital results in a rate of symptomatic VTE, 5 weeks after operation, of just under 4\%. Extending prophylaxis for 5 weeks reduces the rate to $1.3 \%$. Most surgeons would argue that is an important reduction.

Faculty: An analogy is the threshold for primary prophylaxis of febrile neutropenia. The recommendations are to provide prophylaxis to patients at greater than $20 \%$ risk.

Faculty: The high threshold for prophylaxis of neutropenia is driven, at least in part, by the cost of therapy. Prophylaxis for DVT, even with LMWHs, is quite inexpensive.

Faculty: Perception also drives clinical practice. A recent publication suggested that $25 \%$ of breast surgeons and oncologists are not aware of the thromboembolic risks associated with cancer. In qualitative studies with oncologists and palliative care physicians, perception is that VTE is not a major problem.

Faculty: Part of the issue is the clinician's individual experience. Until recently, the primary option for thromboprophylaxis was warfarin, and the burden and hazards of warfarin are often not considered worthwhile. Today, we can give LMWH, but there is a perception that we are burdening the patient with a daily selfadministered injection. In short, there are multiple factors driving the decision to provide thromboprophylaxis that have little to do with efficacy.

\section{CONSENSUS STATEMENT}

As venous thromboprophylaxis gains acceptance as a quality measure that requires risk assessment in the UK health-care system (National Institute for Health and Clinical Excellence, 2009), clinicians will be required to perform a risk assessment on hospital admission, adhere to national guidelines for detection of VTE (National Institute for Health and Clinical Excellence, 2010), provide adequate thromboprophylaxis for all surgical oncology patients and high-risk medical oncology patients, and monitor and document thromboembolic outcomes for all patients with cancer, including health economic outcomes.

Recent publications that have not supported the use of GCS as a thromboprophylactic measure for acute stroke patients admitted to hospital have thrown doubt on the value of GCS as a thromboprophylactic modality, but this finding should not be extended to all mechanical devices. It is clear, however, that GCS should not be used as the only thromboprophylactic measure in immobile medical patients.

\section{REFERENCES}

Agnelli G, Bergqvist D, Cohen AT, Gallus AS, Gent M, on behalf of PEGASUS investigators. Randomized clinical trial of postoperative fondaparinux $v s$ perioperative dalteparin for prevention of venous thromboembolism in high-risk abdominal surgery. $B r J$ Surg 92: $1212-1220$

Alcalay A, Wun T, Khatri V, Chew HK, Harvey D, Zhou H, White RH (2006) Venous thromboembolism in patients with colorectal cancer: incidence and effect on survival. J Clin Oncol 24: 1112-1118

Bennett CL, Angelotta C, Yarnold PR, Evens AM, Zonder JA, Raisch DW, Richardson P (2006) Thalidomide- and lenalidomide-associated thromboembolism among patients with cancer. JAMA 296: 2558-2560

Bergqvist D, Agnelli G, Cohen AT, Eldor A, Nilsson PE, Le Moigne-Amrani A, Dietrich-Neto F, for ENOXACAN II investigators (2002) Duration of prophylaxis against venous thromboembolism with enoxaparin after surgery for cancer. $N$ Engl J Med 346: $975-980$

Blom JW, Doggen CJ, Osanto S, Rosendaal FR (2005) Malignancies, prothrombotic mutations, and the risk of venous thrombosis. JAMA 293: $715-722$

Bona RD, Sivjee KY, Hickey AD, Wallace DM, Wajcs SB (1995) The efficacy and safety of oral anticoagulation in patients with cancer. Thromb Haemost 74: 1055-1058
Implementation of known thromboprophylaxis evidence is difficult in the United Kingdom. The scale of the thrombosis and malignancy challenge should be regularly highlighted to the UK oncology community. Implementation of thromboprophylaxis in patients with cancer may be hampered by several concerns that warrant discussion at the hospital Trust level. These concerns include fear of bleeding complications (particularly with warfarin) and other side effects of medication (e.g., the risk for HIT conferred by heparins). Evidence suggests that the risk for bleeding among patients who receive pharmacological prophylaxis is low among surgical oncology patients without significant bleeding risk factors (Leonardi et al, 2006) and the risk for HIT is $<1 \%$ with LMWHs (Warkentin and Greinacher, 2004).

Every patient with malignancy should be regularly assessed for risk of VTE as part of the standard procedure for hospital attendance. The 'Risk Assessment for Venous Thromboembolism' tool, developed by the UK Chief Medical Officer's Expert Advisory Group (National Institute for Health and Clinical Excellence, 2009), should be used as a minimum standard.

Additional appropriately powered clinical trials are required to show the benefits and/or risks of mechanical, pharmacological, and inferior vena caval filter thromboprophylaxis in the cancer population. Pharmacological trials with new agents are best conducted in patient populations with specific tumours, particularly in high-risk tumour groups (e.g., pancreas, stomach, kidney, bladder, uterus, and lung) (Chew et al, 2006) and in medical oncology patients. With the shift of emphasis of care to the community, ambulatory and hospitalised patients should be considered for clinical trials.

Patients with cancer are a particularly vulnerable group for whom appropriate assessment and adequate thromboprophylaxis are essential for those undergoing surgery. All other patients with malignancy require regular assessment and appropriate treatment, according to their risk of thrombosis. The forthcoming National Institute for Health and Clinical Excellence final guidelines, 'Prophylaxis of Venous Thromboembolism in Hospitalised $\mathrm{Pa}-$ tients,' in early 2010 (National Institute for Health and Clinical Excellence, 2010) will provide a framework for improved quality thromboprophylaxis care in the United Kingdom, implemented at the hospital Trust level.

\section{Conflict of interest}

A Stanley has received consulting fees from Roche, Lilly, MSD, Pfizer, BMS, GSK, and Merck, as well as lecture fees from BCPS Merck. A Young has declared no financial interests.

Cavo M, Zamagni E, Cellini C, Tosi P, Cangini D, Cini M, Valdrè L, Palareti G, Masini L, Tura S, Baccarani M (2002) Deep vein thrombosis in patients with multiple myeloma receiving first-line thalidomidedexamethasone therapy. Blood 100: 2272-2273

Chaukiyal P, Nautiyal A, Radhakrishnan S, Singh S, Navaneethan S (2008) Thromboprophylaxis in cancer patients with central venous catheters. A systematic review and meta-analysis. Thromb Haemost 99: $38-43$

Chew HK, Wun T, Harvey D, Zhou H, White RH (2006) Incidence of venous thromboembolism and its effect on survival among patients with common cancers. Arch Intern Med 166: $458-464$

Clagett GP, Reisch JS (1998) Prevention of venous thromboembolism in general surgical patients. Ann Surg 208: $227-240$

Cohen AT, Davidson BL, Gallus AS, Lassen MR, Prins MH, Tomkowski W, Turpie AG, Egberts JF, Lensing AW, ARTEMIS Investigators (2006) Efficacy and safety of fondaparinux for the prevention of venous thromboembolism in older acute medical patients: randomised placebo controlled trial. BMJ 332: 325-329

Dennis M, Sandercock PA, Reid J, Graham C, Murray G, Venables G, Rudd A, Bowler G (2009) Effectiveness of thigh-length graduated compression stockings to reduce the risk of deep vein thrombosis after 
stroke (CLOTS trial 1): a multicentre, randomised controlled trial CLOTS Trials Collaboration. Lancet 373: $1958-1965$

Eriksson BI, Dahl OE, Rosencher N, Kurth AA, van Dijk CN, Frostick SP, Prins MH, Hettiarachchi R, Hantel S, Schnee J, Buller HR, RE-NOVATE Study Group (2007a) Dabigatran etexilate $v s$ enoxaparin for prevention of venous thromboembolism after total hip replacement: a randomised, double-blind, non-inferiority trial. Lancet 370: 949-956

Eriksson BI, Dahl OE, Rosencher N, Kurth AA, van Dijk CN, Frostick SP, Kälebo P, Christiansen AV, Hantel S, Hettiarachchi R, Schnee J, Büller HR, RE-MODEL Study Group (2007b) Oral dabigatran etexilate vs subcutaneous enoxaparin for the prevention of venous thromboembolism after total knee replacement: the RE-MODEL randomized trial J Thromb Haemost 5: 2178-2185

Eriksson BI, Kakkar AK, Turpie AG, Gent M, Bandel TJ, Homering M, Misselwitz F, Lassen MR (2009) Oral rivaroxaban for the prevention of symptomatic venous thromboembolism after elective hip and knee replacement. J Bone Joint Surg Br 91: 636-644

Geerts WH, Bergqvist D, Pineo GF, Heit JA, Samama CM, Lassen MR, Colwell CW (2008) Prevention of venous thromboembolism: American College of Chest Physicians Evidence-Based Clinical Practice Guidelines (8th Edition). Chest 133: 381S-453S

Heit JA, Silverstein MD, Mohr DN, Petterson TM, O'Fallon WM, Melton III LJ (2000) Risk factors for deep vein thrombosis and pulmonary embolism: a population-based case-control study. Arch Intern Med 160: $809-815$

HES Online. Hospital Episodes Statistics 2007-2008. http://www.hesonline org.uk/Ease/servlet/ContentServer?siteID $=1937 \&$ categoryID $=193$. Accessed August 24, 2009

Hirsh J, Bauer KA, Donati MB, Gould M, Samama MM, Weitz JI (2008) Parenteral anticoagulants: American College of Chest Physicians Evidence-Based Clinical Practice Guidelines (8th Edition). Chest 133: $141 S$ - 159 S

Hutten BA, Prins MH, Gent M, Ginsberg J, Tijssen JG, Buller HR (2000) Incidence of recurrent thromboembolic and bleeding complications among patients with venous thromboembolism in relation to both malignancy and achieved international normalized ratio: a retrospective analysis. J Clin Oncol 18: $3078-3083$

Jiang X, Crain EJ, Luettgen JM, Schumacher WA, Wong PC (2009) Apixaban, an oral direct factor Xa inhibitor, inhibits human clot-bound factor Xa activity in vitro. Thromb Haemost 101: 780-782

Kakkar AK, Levine M, Pinedo HM, Wolff R, Wong J (2003) Venous thrombosis in cancer patients: insights from the FRONTLINE survey. Oncologist 8: $381-388$

Kakkar AK, Levine MN, Kadziola Z, Lemoine NR, Low V, Patel HK, Rustin G, Thomas M, Quigley M, Williamson RC (2004) Low molecular weight heparin, therapy with dalteparin, and survival in advanced cancer: the fragmin advanced malignancy outcome study (FAMOUS). J Clin Oncol 22: $1944-1948$

Kirkpatrick A, Rathbun S, Whitsett T, Raskob G (2007) Prevention of central venous catheter-associated thrombosis: a meta-analysis. Am J Med 120: 901.e1-901.e13

Lassen MR, Ageno W, Borris LC, Lieberman JR, Rosencher N, Bandel TJ, Misselwitz F, Turpie AG, RECORD3 Investigators (2008) Rivaroxaban vs enoxaparin for thromboprophylaxis after total knee arthroplasty. $N$ Engl J Med 358: $2776-2786$

Leizorovicz A, Turpie AG, Cohen AT, Wong L, Yoo MC, Dans A, for the SMART Study Group (2005) Epidemiology of venous thromboembolism in Asian patients undergoing major orthopedic surgery without thromboprophylaxis. The SMART Study. J Thromb Haemost 3: 28-34

Leonardi MJ, McGory ML, Ko CY (2006) A systematic review of deep venous thrombosis prophylaxis in cancer patients: implications for improving quality. Ann Surg Oncol 14: 929-936
Levine M, Hirsh J, Gent M, Arnold A, Warr D, Falanga A, Samosh M, Bramwell V, Pritchard KI, Steward D, Warr D, Goodwin P, Samosh M, Falanga A (1994) Double-blind randomised trial of a very-low-dose warfarin for prevention of thromboembolism in stage IV breast cancer. Lancet 343: $886-889$

Lyman GH, Khorana AA, Falanga A, Clarke-Pearson D, Flowers C, Jahanzeb M, Kakkar A, Kuderer NM, Levine MN, Liebman H, Mendelson D, Raskob G, Somerfield MR, Thodiyil P, Trent D, Francis CW (2007) American Society of Clinical Oncology guideline: recommendations for venous thromboembolism prophylaxis and treatment in patients with cancer. J Clin Oncol 25: 5490-5505

Mandalá M, Falanga A, Roila F, on behalf of ESMO Guidelines Working Group. Management of venous thromboembolism in cancer patients: ESMO clinical recommendations. Ann Oncol 19(suppl 2): ii126 - ii127

National Institute for Health and Clinical Excellence (2009) Venous thromboembolism (VTE) risk assessment. http://www.dh.gov.uk/en/ Publicationsandstatistics/Publications/PublicationsPolicyAndGuidance/ DH_088215. Accessed August 24, 2009

National Institute for Health and Clinical Excellence (2010) Reducing the risk of venous thromboembolism (deep vein thrombosis and pulmonary embolism) in patients admitted to the hospital. http:// www.nice.org.uk/guidance/index.jsp?action=byID\&o=12695. Accessed August 24, 2009.

Prandoni P, Lensing AW, Piccioli A, Bernardi E, Simioni P, Girolami B, Marchiori A, Sabbion P, Prins MH, Noventa F, Girolami A (2002) Recurrent venous thromboembolism and bleeding complications during anticoagulant treatment in patients with cancer and venous thrombosis. Blood 100: $3484-3488$

Rajkumar SV, Blood E, Vesole D, Fonseca R, Greipp PR (2006) Phase III clinical trial of thalidomide plus dexamethasone compared with dexamethasone alone in newly diagnosed multiple myeloma: a clinical trial coordinated by the Eastern Cooperative Oncology Group. J Clin Oncol 24: $431-436$

Samama MM, Cohen AT, Darmon JY, Desjardins L, Eldor A, Janbon C, Leizorovicz A, Nguyen H, Olsson CG, Turpie AG, Weisslinger N, for the Prophylaxis in Medical Patients with Enoxaparin Study Group (1999) A comparison of enoxaparin with placebo for the prevention of venous thromboembolism in acutely ill medical patients. $N$ Engl J Med 341: $793-800$

Shantsila E, Lip GY (2008) Apixaban, an oral, direct inhibitor of activated factor Xa. Curr Opin Investig Drugs 9: 1020-1033

Turpie AG, Lassen MR, Davidson BL, Bauer KA, Gent M, Kwong LM, Cushner FD, Lotke PA, Berkowitz SD, Bandel TJ, Benson A, Misselwitz F, Fisher WD, RECORD4 Investigators (2009) Rivaroxaban vs enoxaparin for thromboprophylaxis after total knee arthroplasty (RECORD4): a randomised trial. Lancet 373: $1673-1680$

Warkentin T, Greinacher A (2004) Heparin-induced thrombocytopenia: recognition, treatment, and prevention: the Seventh ACCP Conference on Antithrombotic and Thrombolytic Therapy. Chest 126: 311S - 337S

Young AM, Billingham LJ, Begum G, Kerr DJ, Hughes AI, Rea DW, Shepherd S, Stanley A, Sweeney A, Wilde J, Wheatley K, WARP Collaborative Group, UK. Warfarin thromboprophylaxis in cancer patients with central venous catheters (WARP): an open-label randomised trial. Lancet 373: 567-574

Zacharski LR, Prandoni P, Monreal M (2005) Warfarin vs low-molecular weight heparin therapy in cancer patients. Oncologist 10: $72-79$

Zangari M, Anaissie E, Barlogie B, Badros A, Desikan R, Gopal AV, Morris C, Toor A, Siegel E, Fink L, Tricot G (2001) Increased risk of deep-vein thrombosis in patients with multiple myeloma receiving thalidomide and chemotherapy. Blood 98: 1614-1615 